with ILD periodically perform pulmonary function tests to monitor lung function evolution.

Results: At now, 205 RA patients have been enrolled (female/male 161/44, mean age $64.8 \pm 12.9$ years, mean disease duration $14.2 \pm 8.9$ years), anti-citrullinated peptides antibodies (ACPA) and rheumatoid factor (RF) were positive in $77.1 \%$ and $78.1 \%$, respectively. The prevalence of ILD was $21 \%$ (43 patients). In other 13 patients the HRCT is ongoing; therefore, we could suppose up to a prevalence of $27.3 \%$. Patients with ILD were symptomatic in $53.5 \%$ of cases $(23$ patients), they are more frequently males and were older than patients without ILD (mean age $73.2 \pm 7.4$ and $62.7 \pm 13.2 ; \mathrm{p}<0.0001$, female/male ratio $139 / 23$ vs $22 / 21 ; p<0.0001$ ) without significant differences regarding disease duration, positivity for ACPA or RF.

Conclusion: The prevalence and the incidence of RA-ILD is still not well defined. Preliminary data of our study confirm a prevalence of ILD higher than $20 \%$, patients are asymptomatic in almost the half of cases and more frequently males and elderly. Our study can help to define the clinical history of these patients, the possible association with clinical and serological features and the supposed role of some drugs.

References:

[1] Manfredi A, et al. Diagnostic accuracy of a velcro sound detector (VECTOR) for interstitial lung disease in rheumatoid arthritis patients: the InSPIRAtE validation study (INterStitial pneumonia in rheumatoid ArThritis with an electronic device). BMC Pulm Med. 2019;19:111.

[2] Bendstrup E, et al. Interstitial Lung Disease in Rheumatoid Arthritis Remains a Challenge for Clinicians. J Clin Med. 2019:8

Disclosure of Interests: Marco Sebastiani: None declared, Caterina Vacchi: None declared, Giulia Cassone: None declared, Fabiola Atzeni: None declared, Martina Biggioggero: None declared, Antonio Carriero: None declared, Gian Luca Erre: None declared, Anna Laura Fedele: None declared, Federica Furini: None declared, Paola Tomietto: None declared, Vincenzo Venerito: None declared, Belén Atienza-Mateo: None declared, Giovanni Della Casa: None declared, Stefania Cerri: None declared, Gilda Sandri: None declared, Adalgisa Palermo: None declared, Elena Galli: None declared, Fabrizio Pancaldi: None declared, Miguel A González-Gay Grant/research support from: Pfizer, Abbvie, MSD, Speakers bureau: Pfizer, Abbvie, MSD, Carlo Salvarani: None declared, Andreina Manfredi: None declared

DOI: 10.1136/annrheumdis-2020-eular.3516

\section{THU0151 RISK OF MALIGNANCIES ASSOCIATED WITH CS DMARDS IN RHEUMATOID ARTHRITIS: COMPARISON WITH GENERAL POPULATION AND BIOLOGIC TREATED PATIENTS (ANALYSIS OF A NATIONAL CLAIM DATABASE)}

R. Seror ${ }^{1}$, A. Lafourcade ${ }^{2}$, Y. De-Rycke ${ }^{2}$, B. Fautrel ${ }^{3}$, X. Mariette ${ }^{1}$, F. Tubach ${ }^{2}$. ${ }^{1}$ Hopitaux Universitaires Paris-Saclay, Rheumatology, Le Kremlin-Bic être, France; ${ }^{2}$ Pitié-Salpêtrière Hospital, Biostatistics, Public Health and Medical Information, Paris, France; ${ }^{3}$ Pitié-Salpêtrière Hospital, Rheumatology, Paris, France

\section{Background:}

Objectives: To estimate the incidence rate of malignancies in csDMARD-treated RA patients and to compare it to that of general population and to biologic-treated RA patients

Methods: We conducted an historical cohort study within the national claim database that prospectively records individual health resource use of $86 \%$ of the French population (65 million inhabitants). RA adult patients were identified based on ICD-10 code (M05 or M06) between 2007-2016. Patients with previous cancer history were excluded. Treatment exposures were incident first use of any treatment: csDMARD (methotrexate, leflunomide, sulfasalazine, azathioprine, hydroxychloroquine) or biologics (anti-TNF, rituximab, abatacept, tocilizumab, ustekinumab, anakinra). To identify incident treatment periods, only patients who did not receive any treatment in the 1-year period before the index date were selected. Exposure was defined with a 90-day latency after treatment initiation and a 180-day carry-over period after drug discontinuation.

To compare the risk of malignancies between csDMARD-treated patients and general population, standardized incidence ratio (SIR $[95 \% \mathrm{Cl}]$ ) were calculated using FRANCIM ("France Cancer Incidence et Mortalité") estimations as reference.

To compare the risk of malignancies between csDMARD and biologics treated patients, a dynamically propensity score (including age, sex, year of first occurrence of RA code, date of treatment initiation, number of previous DMARDs, Charlson's comorbidity index, diagnosis of tobacco and/or alcohol-associated disorders, number of hospitalizations for RA, cumulative corticosteroid dose) was constructed using pooled logistic regression. Hazard Ratios (HRs) for risk of cancer were estimated using Cox proportional hazards model after dynamically propensity score matching. Exposure was considered as a time-dependent variable.
Results: Between 2007 and 2016, 83,706 RA patients exposed to csDMARD $(n=63,837)$ and/or biologics $(n=19,727)$ were identified.

As compared to the general population, csDMARDs treated patients had an increased risk of lung cancer ( $\mathrm{SIR}=1.29[1.14 ; 1.45])$, invasive melanoma $(\mathrm{SIR}=1.52[1.24 ; 1.86])$ and a borderline increased risk of breast cancer $(\mathrm{SIR}=1.11$ [1.01;1.22]). By contrast, they had a decreased risk of pancreatic cancer $(\mathrm{SIR}=0.68[0.51-0.9])$ and liver cancer $(\mathrm{SIR}=0.43[0.27 ; 0.67])$. This later is due to a protopathic bias.

\section{Overall risk of malignancies}

(excl. non melanoma skin cancer)

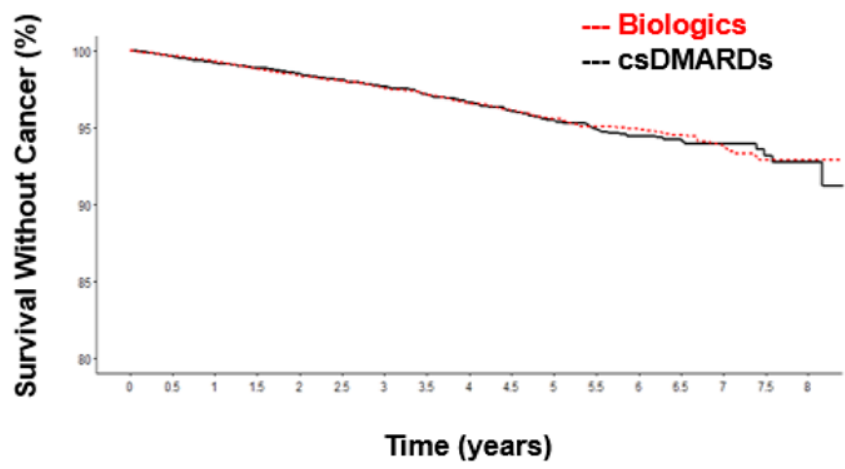

After propensity score matching, analyses the risk of malignancies between CSDMARD and biologics treated patients were conducted on 19727 patients in each group (mean age: $51 \pm 14$ yrs; female: $74.6 \%$ ). Malignancies occurred in 435 patients exposed to biologics and 332 patients exposed to csDMARD. The overall risk of malignancies (figure), risk of solid cancer (excluding non-melanoma skin cancer), lymphoma, and other hematologic malignancies did not differ significantly between cSDMARD and all biologics (table). Regarding organ specific cancer, no difference was observed. Results were similar for biologic in monotherapy or associated with csDMARD.

\begin{tabular}{lcc}
\hline Type of malignancies & $\begin{array}{c}\text { HR [95\%Cl] csDMARD } \\
\text { (ref) vs. all biologics }\end{array}$ & $\mathrm{p}$-value \\
\hline All malignancies (excl. non-melanoma skin cancer) & $0.99[0.86 ; 1.14]$ & $\mathrm{p}=0.9$ \\
Solid cancer (excl. non-melanoma skin cancer) & $0.95[0.82 ; 1.11]$ & $\mathrm{p}=0.5$ \\
Lymphoma & $1.35[0.72 ; 2.53]$ & $\mathrm{p}=0.3$ \\
Other hematologic malignancies & $1.18[0.56 ; 2.49]$ & $\mathrm{p}=0.7$
\end{tabular}

Conclusion: Using a large nationwide representative healthcare database, the overall risk of malignancies and the risk of organ-specific cancers and hematologic malignancies in biologic treated RA patients did not differ from that of patients treated with csDMARD. Compared to general population, patients treated with csDMARD had an increased risk of lung cancer and melanoma, but a decreased risk of pancreatic cancer.

Disclosure of Interests: Raphaèle Seror Consultant of: BMS, Medimmune, Novartis, Pfizer, GSK, Lilly, Alexandre Lafourcade: None declared, yann de-rycke: None declared, Bruno Fautrel Grant/research support from: AbbVie, Lilly, MSD Pfizer, Consultant of: AbbVie, Biogen, BMS, Boehringer Ingelheim, Celgene, Lilly, Janssen, Medac MSD France, Nordic Pharma, Novartis, Pfizer, Roche, Sanofi Aventis, SOBI and UCB, Xavier Mariette Consultant of: BMS, Gilead, Medimmune Novartis, Pfizer, Servier, UCB, Florence Tubach Grant/research support from: Florence TUBACH is head of the Centre de Pharmacoépidémiologie (Cephepi) of the Assistance Publique - Hôpitaux de Paris and of the Clinical Research Unit of Pitié-Salpêtrière hospital, both these structures have received research funding, grants and fees for consultant activities from a large number of pharmaceutical companies, that have contributed indiscriminately to the salaries of its employees. Florence Tubach didn't receive any personal remuneration from these companies. DOI: 10.1136/annrheumdis-2020-eular.3656

\section{\begin{tabular}{|l|l}
\hline THU0152 THE ADVANTAGES OF DISTANCE BLOOD PRESSURE \\
\hline
\end{tabular} MONITORING IN PATIENTS WITH RHEUMATOID ARTHRITIS}

I. Starodubtseva ${ }^{1}$, J. Sharapova ${ }^{2} .{ }^{1} N N$ Burdenko Voronezh State Medical University, Internal Diseases, Voronezh, Russian Federation; ${ }^{2}$ NN Burdenko Voronezh State Medical University, Voronezh, Russian Federation

Background: Cardiovascular complications are very common in patients with rheumatoid arthritis (RA). The monitoring of the course of RA and comorbid conditions is the key aspect of the prevention of early mortality. 